\title{
COLLECTION OF STRATOSPHERIC MICROPARTICLES ABOVE THE SULFATE LAYER USING BALLOON-BORNE COLLECTORS
}

\author{
J. R. STEPHENS ${ }^{1}$, Y. NAKADA ${ }^{2}$, T. ONAKA ${ }^{2}$, F. J. M. RIETMEIJER ${ }^{3}$ \\ 1 Los Alamos National Laboratory, Los Alamos, New Mexico 87545, U.S.A. \\ 2 Department of Astronomy, Faculty of Science, Univ. of Tokyo, Tokyo 113, Japan. \\ 3 Department of Geology, University of New Mexico, Albuquerque, NM 87131, USA.
}

\begin{abstract}
We report preliminary analytical electron microscope (AEM) analysis of nearly 300 stratospheric particles collected using balloon-borne collectors at $34-36 \mathrm{~km}$ altitude. The particles are predominantly silica, plagioclase feldspar, $\mathrm{Mg}$, Fe-silicates and rare barite, metal oxides, and unidentified $\mathrm{Fe}, \mathrm{Ni}, \mathrm{Zn}$, and $\mathrm{Pb}$ particles. The majority of these generally submicron-sized particles are comparable to volcanic particles collected at $20 \mathrm{~km}$ altitude from the 1982 eruption of the El Chichon volcano. Because of the uniqueness in altitude and collected particle sizes the collection may also contain interplanetary dust particles of types poorly represented in present collections.
\end{abstract}

\section{Introduction}

Particles may be injected into the stratosphere from large volcanic eruptions [D'Altorio and Visconti, 1983], form by gas to particle transformations, or by introduction of extraterrestrial particles or vapors [Hughes, 1978]. Above the sulfate layer $(>33 \mathrm{~km}$ ) it is expected that extraterrestrial particles dominate the stratospheric particle population. Most of the small extraterrestrial particles that enter the earth's atmosphere vaporize at altitudes between 80 and $100 \mathrm{~km}$ and are believed to form refractory grain condensates. Hunten et al., 1980 modeled the formation of condensates from meteoritic vapors. They considered the chemical reactions regulating particle formation from vapors including nucleation, condensation, and coagulation.

Volcanic particles are periodically injected to high altitudes. For example, the El Chichon volcanic event injected particles to between 33 and $35 \mathrm{~km}$ during 1982 [Coulson et al., 1982]. Small, micron-sized particles have settling times on the order of years in the stratosphere [Mackinnon et al., 1984].

In May 1985 stratospheric particles were collected at $34-46 \mathrm{~km}$ using a high-altitude balloon, the initial results of which have been reported [Testa et al., 1990]. The balloon-borne collector captured solid particles $(<0.045-10.0 \mu \mathrm{m}$ diameter $)$ using cascade impactors and filters. Particle concentration, size distribution, and bulk elemental composition were measured on a major portion of the collected particles using scanning electron microscope (SEM) and protoninduced X-ray emission (PIXE) instruments. The particles in the collection complement the existing particle collections now obtained up to 20 kilometers using high altitude aircraft such as the Lockheed U-2 [Brownlee, 1978].

A.C. Levasseur-Regourd and H. Hasegawa (eds.), Origin and Evolution of Interplanetary Dust, 49-52. (C) 1991 Kluwer Academic Publishers, Printed in Japan. 
We report here a detailed analysis of several hundred of the collected particles including particle morphology, major element data, and electron diffraction data. Comparison of the elemental and morphological data with characteristics of known extraterrestrial and volcanic particles is made in an attempt to deduce the origin of the collected particles.

\section{Experimental}

The particles were collected using a balloon-borne instrument that employed three parallel collectors each consisting of a combination of a single stage cascade impactor followed by a Nuclepore Membrane Filter (NMF) filter. One collector, used to collect particles for particle counting, used NMF's for both the impact surface and filter. A second collector, used to collect particles for analytical electron microscope (AEM) analysis, consisted of nine holey-carbon filmed beryllium AEM grids glued to a NMF impact surface in a cross pattern followed by a NMF used as a filter. The third "flight blank" collector had the same configuration as the first collector but was not attached to a pump and received no flow during the flight. Upon collection the samples were placed in sealed containers and stored in a laminar-flow clean bench.

Particles measured in this study were present on 3 TEM grids. No sample preparation was used prior to inserting the grids into microscope. The dust grains occur dispersed on holeycarbon thin films that are supported by Be TEM grids. Particles were examined using a JEOL $2000 \mathrm{FX}$ AEM which is operated at an accelerating voltage of $200 \mathrm{kV}$. The TEM grids are housed in a Gatan low-background, double-tilt specimen holder during analysis using secondary and transmitted electrons for TEM and SEM imaging and X-rays for in situ chemical micro-analysis using a probe size of $\sim 20 \mathrm{~nm}$ in diameter. Semi-quantitative chemical data were obtained for $\mathrm{Na}$ and heavier elements using a Tracor-Northern TN5500 energy dispersive spectrometer (EDS). Particles with morphologies characteristic of poorly graphitized carbon, which are formed during production of the carbon film on the grids, were rejected from the particle counts based on their unique morphology and lack of X-ray spectra [Reitmeijer, 1985].

\section{Results}

Concentrations of particles between 0.045 and $1.0 \mu \mathrm{m}$ were at least 50 times the handling blank levels and 30 to $10^{4}$ times the concentrations predicted by the model of Hunten et al., 1980 . The observed particle concentration is similar to concentrations measured by balloon-borne particle counters and SAGE II satellite extinction observations between November 29, 1984 and October 11, 1986 [Osborn et al., 1989].

The majority of the particles are angular shards of silica, plagioclase $\left(\mathrm{CaAl}_{2} \mathrm{Si}_{2} \mathrm{O} 8\right), \mathrm{Mg}, \mathrm{Fe}-$ silicates (including pyroxenes and olivines), rare grains of barite ( $\left.\mathrm{BaSO}_{4}\right)$, and oxides of $\mathrm{Pb}$, $\mathrm{Fe}, \mathrm{Bi}$, and $\mathrm{Al}$. The silica and silicate minerals constitute $83 \%$ of all particles collected. Individual particle sizes ranged from 0.5 to $5.0 \mu \mathrm{m}$. In addition to the particles listed above, unidentified particles containing $\mathrm{Fe}, \mathrm{Ni}, \mathrm{Zn}$ and $\mathrm{Pb}$, and occasionally sulfur [Rietmeijer, 1990] were seen. Approximately $74 \%$ of the particles by number are $<\sim 1.0 \mu \mathrm{m}$ in size with $17 \%$ of particles $<\sim 0.2 \mu \mathrm{m}$. Clusters of silica, silicate, and barite grains, in variable proportions are common. In addition nanometer-size $\mathrm{NaCl}$ and $\mathrm{KCl}$ crystallites and sulfuric acid droplets are seen adhering to the particle surfaces. An example of a cluster particle is shown in Figure 1. 


\section{Discussion}

Our particles show platey shard morphology, a high concentration of clusters and also silica particles with adhered salts and sulfuric acid droplets that are most similar to stratospheric aircraft collections of volcanic particles from the El Chichon event [Mackinnon et al., 1984]. Volcanic particles show characteristic mineralogy and chemistry consisting of angular silica-rich grains, particle clusters, and particles containing large amounts of metals including $\mathrm{Cu}$ and $\mathrm{Pb}$. The presence of a high concentration of micron-sized volcanic particles after several years requires an efficient mechanism for lofting submicron particles in the stratosphere. Extraterrestrial cluster particles collected by aircraft in the stratosphere predominantly consist of pyroxenes and olivines plus carbonaceous materials and typically have a chondritic major element composition. We have not yet found this type of particle in our collection.

Some of our particles could be a unique class of extraterrestrial particles smaller than $1 \mu \mathrm{m}$ that impact the stratosphere. For example, iron oxide particles in our collection may be of meteoric origin. Such particles would not be collected in aircraft flights due to the aircraft collector size cutoff above this size. A larger flux of submicron micrometeoroids than previously thought is in accord with high particle counts found on an aircraft collection flag down to the lowest size collection limit $(\sim 1 \mu \mathrm{m})$ [Zolensky and Mackinnon, 1985]. Alternatively, some of our particles may have formed by breakup of larger porous micrometeoroids composed of low strength aggregates of submicron grains. More collections are necessary to resolve the genesis of the small particles in our collection.

\section{REFERENCES}

D. E. Brownlee, Microparticle studies by sampling techniques, in: Cosmic Dust, J. A. M. McDonnell, ed., pp. 295-366, John Wiley, New York, 1978.

K. E. Coulson, T. E. Defour, J. Deluis, LIDAR and optical polarization measurements of stratospheric cloud in Hawaii, EOS, Trans. Am. Geophys. Union, 63, 897, 1982.

A. D'Altorio and G. Visconti, LIDAR observations of dust layers transient in the stratosphere following the El Chichon volcanic eruption, Geophys. Res. Letters, 10, 27-30, 1983.

D. W. Hughes, Meteors, in: Cosmic Dust, J. A. M McDonnell, ed., pp. 123-186, John Wiley, New York, 1978.

D. M. Hunten, R. P. Turco and O. B. Toon, Smoke and dust particles of meteoric origin in the mesosphere and stratosphere, J. of Atmos. Sci., $\underline{32}$, 1342-1357, 1980.

I. D. R. Mackinnon, J. L. Gooding, D. S. McKay, and U. S. Clanton, The El Chichon stratospheric cloud: Solid particulates and settling rates, J. Volcanol. and Geotherm. Res., $\underline{23}$, 125-146, 1984.

M. T. Osborn, J. M. Rosen, M. P McCormick, P. Wang, J. Livingston, and T. J. Swissler, SAVE II aerosol correlative observations: profile measurements, J. Geophys. Res. 94, 8353$8366,1989$. 
F. J. M. Rietmeijer, A poorly graphitized carbon contaminant in studies of extraterrestrial materials, Meteoritics 20, 43-48, 1985.

F. J. M. Rietmeijer, El Chichon dust a persistent problem, Nature, 344, 114-115, 1990.

J. P. Testa, J. R. Stephens, W. W. Berg, T. A. Cahill, T. Onaka, Y. Nakada, J. R. Arnold, N. Fong, and P. D. Sperry, Collection of Microparticles at High Balloon Altitude in the Stratosphere, Earth and Planet. Sci. Lett, 98, 287-302, 1990.

M. E. Zolensky and I. D. R. Mackinnon, Accurate stratospheric particles size distributions from a flat plate collection surface, J. Geophys. Res. 90, 5801-5808, 1985.

\section{Figure 1:}

A composite cluster of plagioclase, tridymite, and $\mathrm{Mg}, \mathrm{Fe}$-silicate (probably low-Ca pyroxene) shards. The background is a holey-carbon support film. The filaments are glue used to adhere the grids to the impact surface.

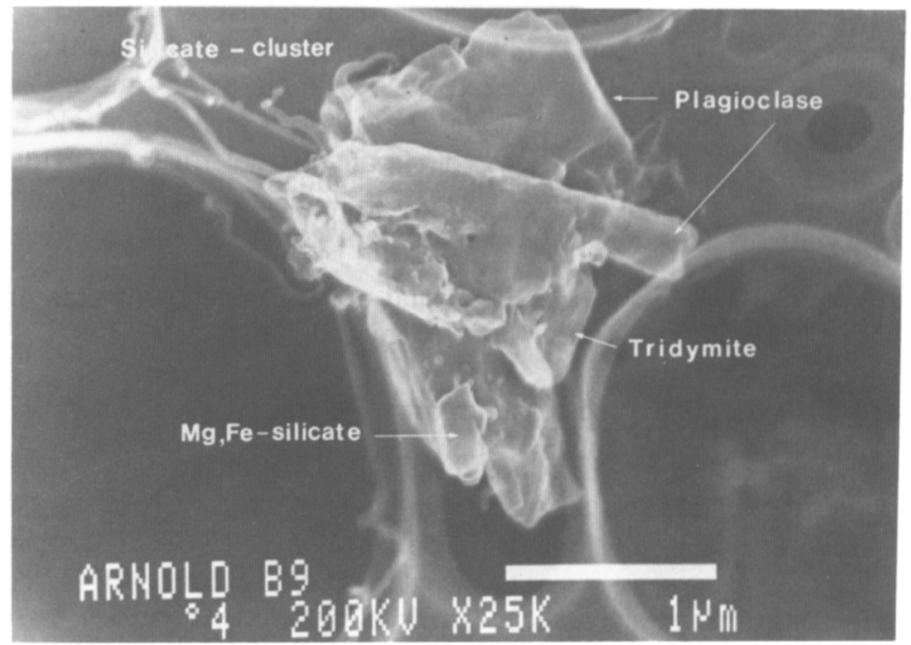

